\title{
ENTREVISTA
}

\section{Cayetano del Toro y Quartiellers: biografía, obra y pensamiento}

El investigador Ángel Guisado Cuéllar, miembro del CEHME, ha defendido su tesis doctoral con el título "Cayetano del Toro y Quartiellers: biografía, obra y pensamiento" en la Facultad de Filosofía y Letras de la Universidad de Cádiz, el pasado 31 de mayo de 2017, obteniendo la calificación de sobresaliente cum laude.

Ángel Guisado Cuéllar nació en Cádiz (España) en 1969, dedicando su actividad investigadora a la ilustración, el liberalismo, el romanticismo y la democracia (siglos XVIII-XXI) en la Universidad de Cádiz. El autor nos ha concedido la siguiente entrevista.

¿Podría explicarnos el título y la materia de su tesis?

Mi tesis doctoral se centra en un personaje gaditano decimonónico (1842-1915) que fue un masón paradigmático de su época y a través del cual puede entenderse el modus vivendi de la época en muchos aspectos, entre ellos, la masonería. Fue un hombre extraordinario por su brillantez en las cuestiones que abordó: medicina, bellas artes, política, literatura, filantropía, entidades culturales, ciencias, coleccionismo, entidades religiosas, docencia, periodismo científico y en la masonería, por ejemplo.

¿Cuáles fueron los motivos que le llevó a enfocar su investigación hacia la Masonería?

Pues, honestamente, mi lugar de nacimiento y de residencia es un lugar que facilita mucho el interés por esta materia. Recordemos que en el siglo XVIII, Cádiz vivió su edad dorada como encrucijada y puerta de las nuevas ideas ilustradas y liberales. La herencia de la Constitución de 1812 sigue presente en el imaginario colectivo y es una seña de identidad para los gaditanos. Por otra parte, su carácter portuario y su proximidad con Gibraltar, propician que no sea un tema que resulte tan extraño como en otras partes de España. Pero realmente, lo que me llevó, de forma indirecta, a estudiar en mayor profundidad a la masonería fue tratar de encontrar alguna explicación al encargo que unos ilustrados gaditanos hicieron a Joseph Haydn para que les compusiese la obra maestra "Las Siete Últimas Palabras de Nuestro Señor en la Cruz" para esa joya arquitectónica y simbólica que es el Oratorio de la Santa Cueva. Un edificio que merece por sí solo una visita a Cádiz para contemplar sus cuadros de Goya, su arquitectura neoclásica exquisita y la de haber provocado la composición de esa partitura magistral de Haydn. Desde el 
estudio de la sociedad gaditana del siglo XVIII, era casi natural el interés por conocer la masonería por ser un elemento palpable aunque no resultase tan evidente a primera vista. Luego, el contacto con diferentes logias, investigadores, el CEHME y el Máster de Historia de la Masonería Española y de América de la UNED terminaron de decidirme a investigar de una manera sistemática y académica.

Volviendo al tema de mi tesis doctoral, Cayetano del Toro fue un ejemplo muy significativo de la situación de la masonería española a finales del siglo XIX. Se inició en una logia gaditana perteneciente al Gran Oriente Lusitano Unido y acabó desentendiéndose de las logias españolas para fundar una bajo el Supremo Consejo de Francia del REAA, con rituales y reglamentos franceses. Curiosamente, la documentación más relevante sobre él se localizó en los archivos de la logia San Juan 115 de Gibraltar, EC, gracias a la colaboración del magnífico investigador y compañero Keith Sheriff. Y, por otra parte, la familia conservó sus rituales, Biblia y algunos enseres masónicos durante más de un siglo. Pocas veces se tiene esta fortuna en este tipo de investigaciones.

¿Cuáles fueron las fuentes que ha utilizado?

Como adelanté en alguna pregunta anterior, fue un hombre multidisciplinar. La búsqueda de información ha sido muy compleja por la cantidad y por la necesaria confrontación de documentos de procedencia diversa. Les expongo un ejemplo: al localizar el cuadro lógico de la logia donde se inició Cayetano del Toro, aparecían muchos de sus compañeros de profesión, cofradía religiosa o partidos políticos. Si quería llegar a entender al personaje y mostrar su verdadera dimensión, era preciso consultar cada archivo para comprobar el comportamiento y actitudes. No bastaba con ceñirnos exclusivamente a los documentos masónicos. Pero debo insistir en un aspecto: la máxima colaboración que he encontrado tanto en la familia del biografiado como en las diferentes instituciones públicas y privadas que me han permitido el acceso a fuentes primarias, secundarias e indirectas. Solamente han existido tres excepciones que no merece la pena citar. En sentido contrario, mi gratitud es infinita a la Fundación Federico Joly Höhr (uno de los archivos privados más importante de España en cuanto a la historia gaditana del siglo XIX, especialmente), la Hermandad de la Santa Caridad (con fondos desde 1597), el Ateneo de Cádiz (fondos desde 1858), la hemeroteca del Diario de Cádiz (con 150 años de antigüedad), archivo de la firma Macpherson (con más de un siglo y medio de antigüedad) y la máxima colaboración de entidades públicas como el Museo de las Cortes de Cádiz, Archivo Municipal de Cádiz, Biblioteca de Temas Gaditanos (Unicaja) o multitud de aportaciones de las diferentes cofradías a las que perteneció el biografiado o de familias de sus discípulos, pacientes o particulares. Por otra parte, también he tenido que recurrir a muchas consultas en archivos extranjeros dada su correspondencia con Academias científicas extranjeras, etc. Realmente, ha sido una búsqueda muy intensa aunque satisfactoria.

Si hablamos en términos académicos, las fuentes primarias no eran demasiadas, excepto 
sus propias publicaciones y las hemerotecas de su época. Las secundarias eran muy escasas dado que era un personaje de difícil estudio dada su complejidad por la amplitud de temas y por tres razones que trataré de apuntar brevemente: a) Cayetano del Toro, en vida, trató siempre de evitar cualquier tipo de homenaje público. A su muerte, la familia trató de mantener esta voluntad de su padre (aunque no lo consiguieron puesto Cádiz tiene un monumento y una avenida dedicada a él); b) Tras su fallecimiento en 1915, España encadenaría épocas convulsas y complejas donde el personaje de Cayetano del Toro no pudo ser usado como mártir ni como símbolo de ninguna facción. Era liberal, católico, masón y de un prestigio intelectual, social así como gestor público que habría hecho sombra a cualquier personaje emergente. No pudo ser instrumentalizado ni para bien ni para mal; y c) en los años sesenta del siglo XX, se le dedicaron algunos estudios parciales sobre su labor médica y muy superficialmente sobre sus otras facetas. Esto indujo a pensar colectivamente que lo publicado era suficiente. No hay mejor manera de ocultar algo que mostrarlo superficialmente.

¿Cuáles han sido las cuestiones históricas más complejas de resolver en su trabajo?

Probablemente, la de verme obligado a empezar desde cero como si no hubiesen existido referencias previas al no ser fiables y estar muy sesgadas por el pensamiento de los autores preconstitucionales. Les pongo un ejemplo. El propio Cayetano del Toro describe en el epílogo de una de sus obras que no pudo acceder a una cátedra por no aceptar pagar un soborno que le ofreció el tribunal. En las fuentes que consulté del siglo XX, esta cuestión distaba mucho de ser explicada de esta manera cuando el protagonista había dejado constancia hasta de la cifra del pretendido soborno: cuatro mil reales de vellón. ¿Por qué esa alteración? Pues porque el autor de la fuente consultada era catedrático de la facultad y no consideraba prudente dar demasiados detalles sobre esta vergonzosa anécdota del pasado. Eran tiempos poco permisibles a ciertas verdades, quiero suponer.

Por otra parte, Cayetano del Toro vivió setenta y dos años de una hiperactividad tremenda. No hubo aspecto de la vida local en que no interviniese de alguna manera. De hecho, su legado en la ciudad sigue muy presente. Decía un contemporáneo suyo que si hubiesen puesto una placa conmemorativa en cada acto que participó o gestión que realizó, la ciudad estaría alicatada con su nombre. Puede sonar exagerado pero el urbanismo actual de la ciudad (Museos, Monumento de las Cortes de 1812, Puerto de Cádiz, astilleros, viviendas de la parte moderna, etc.,) son su legado.

Metodológicamente, la tesis se enfrentaba a dos dificultades: a) ¿adoptar un criterio cronológico o temático? y b) ¿centrarse en un solo aspecto del personaje o en tratar de aportar una visión global? Junto a mi director de tesis, Prof. Dr. Alberto Romero Ferrer, decidimos optar por un tratamiento temático y por asumir el reto de una proyección global. Creo sinceramente que tomamos la decisión más incómoda pero la más beneficiosa para los investigadores especializados que nos sigan.

$\mathrm{Y}$, respecto a las herramientas de investigación, hemos combinado la historiografía, 
heurística y la prosopografía. Era la manera que más ayudaría a una adecuada equidistancia y para lograr una mayor profundidad en las diferentes cuestiones.

Por favor, ¿podría resumir la esencia de sus tesis en dos líneas?

¿Pueden ser tres? Es broma. Entiendo que conocer la biografía, obra y pensamiento de Cayetano del Toro y Quartiellers es conocer la ciencia, el pensamiento y la sociedad de un periodo extremadamente complejo y muy poco estudiado (1842-1915). Queda mucho por profundizar.

¿Cuáles fueron las lecciones, a todos los niveles, que usted ha deducido de su experiencia investigadora?

Si hablo refiriéndome al personaje, es un referente ético e intelectual cuyas ideas innovadoras y sentido común tienen mucho que enseñarnos todavía. En su tiempo se le conoció como "El padre del Pueblo". Creo que no hay mejor galardón ni condecoración que un hombre de bien pueda recibir por parte de sus semejantes. Su herencia no fue económica (apenas dejó bienes materiales habiendo podido ser muy poderoso). Pero su integridad, clarividencia y capacidad extraordinaria de trabajo y sacrificio en beneficio de sus semejantes es algo que asombra en cada hecho estudiado. Uno puede evitar sentirse muy pequeño y humilde ante personajes de esta talla. Y, no lo voy a negar, se echa de menos más no encontrarnos en la vida con más personas de estas características.

Si me tengo que referir a la propia experiencia de investigar, la primera lección es que nunca se acaba. Siempre surgen incógnitas y siempre hay que aceptar que no todo tiene una respuesta inmediata ni indefinida. Creo que hay que ser generoso para compartir el conocimiento que uno va adquiriendo y ser consciente de la responsabilidad de dar a conocer ese conocimiento. No tiene sentido llevarse al otro mundo lo que uno investiga. No somos propietario de ningún descubrimiento, somos meros mecanismos de transmisión. Debemos avanzar todo lo que podamos en nuestras investigaciones para que otros lleguen más lejos aún. El progreso de la Humanidad es una tarea colectiva. Cada uno debería hacer suyo el lema de FIAT LUX.

Esta entrevista se efectúo de forma telemática el 17 de enero de 2018.

Autores de la entrevista: Ricardo Martínez Esquivel e Yván Pozuelo Andrés, director y editor de REHMLAC+, doi: https://doi.org/10.15517/rehmlac.v10i1.32008 